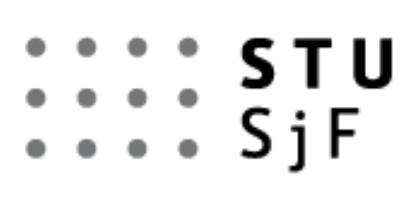

\title{
RESEARCH OF CAVITATION AT HIGH SHEAR STRESS
}

\author{
CSUKA Zoltán ${ }^{1}$, OLŠIAK Róbert ${ }^{1}$, FUSZKO Zoltán ${ }^{1}$ \\ ${ }^{1}$ Slovak University of Technology in Bratislava, Faculty of Mechanical Engineering, \\ Institute of Chemical and Hydraulic Machines and Equipment, Nám. slobody 17, 81231 Bratislava, \\ e-mail: xcsuka.zoltan@gmail.com
}

\begin{abstract}
The article describes the theory of cavitation at high values of shear stress in a viscous liquid. For this purpose, a spatial model of two cylindrical shells imposed concentrically was designed. In the narrow gap between the cylinders the temperature, density and viscosity of liquid is constant. Shear stress is induced by the rotary motion of the inner cylinder, resulting in a change of velocity and pressure fields. Due to the pressure drop between the cylinders there is a precondition to the formation of cavitation bubbles at the point of the lowest static pressure. To verify the assumption was made CFD model based on simplified physical model, through which cavitation was qualitatively and quantitatively assessed. In this paper the results of the numerical solution will be presented alongside with basic form of experimental device for physical generation of cavitation at high values of shear stress.
\end{abstract}

KEYWORDS: shear stress, cavitation, rotating cylinder, pressure drop, narrow gap, turbulence

\section{Introduction}

Cavitation phenomenon has been known for a relatively long time. Inception of cavitation can be induced by various physical methods, but in all cases there is a pressure drop below the vapor pressure of used fluid. This article describes the cavitation effect in the liquid due to shear stress, which involves the interaction of the rotary surface, rotating at high angular velocity and the viscous liquid. The examined volume is filled by a fluid in the narrow gap between the inner rotating surface and the outer stationary surface.

\section{Theoretical background}

Shear stress (1) is induced by the action of friction between the adjacent layers of flowing liquid, depending on the viscosity and flow velocity. For laminar flow applies the equation [1]

$$
\tau=\mu \frac{d u}{d y}
$$

For turbulent flow (2) it is necessary to consider the shear stress in the fluid at the wall, in the boundary layer, where laminar flow is present and further from the wall where the flow has a turbulent character. [1]

$$
\tau_{c e l k}=\tau_{v}+\tau_{\text {turb }}=\mu \frac{d \overline{u_{1}}}{d y}-\rho \overline{u_{1}^{\prime} u_{2}^{\prime}}
$$

Due to this phenomenon in the liquid there is a change in the kinetic energy in the radial direction from the moving wall to the stationary wall. A part of the liquid adjacent to the inner rotating cylinder and the cylinder itself has the identical angular velocity. The part of the 
liquids adjacent to the stationary wall has the same angular velocity as the outer wall itself, which is a zero. The local velocity change has effect on the local change of the static pressure and therefore the total pressure. The progress of the changes in the velocity, perpendicular to narrow gap, depends mainly on the shear stress, so on the angular velocity of rotating walls, radius of the rotating cylinder, the width of the gap and the viscosity of the used liquid. Based on the above mentioned parameters the Reynolds number can be calculated by the equation (3). It determines the flow regime and thus the progress of the velocity curve, or velocity profile, which directly affects the progress of changes in static pressure. In the equation for the Reynolds number the velocity is in the form of circumferential velocity of the rotating inner wall $\Omega_{1}$ on radius $r_{1}$. For this kind of tasks as the characteristic dimension is chosen the width of the gap $d$ between two walls, because the axial dimension in absence of axial velocity doesn't affect the velocity gradient. [2]

$$
R e=\frac{\Omega_{1} r_{1} d}{v}
$$

In this case is the lowest static pressure located in a point where the velocity is the largest. This follows from the law of conservation of energy of flowing liquid. The liquid is moved under its own viscosity by rotation of inner cylindrical surface, which causes a reduction of local static pressure. On the outer non-rotating wall the opposite effect occur. As a consequence of its own viscosity, the fluid is braked by the stationary wall which causes a significant local pressure drop. With the increasing angular velocity of the inner rotary surface, at a given geometry of the narrow gap, when the value of the minimal static pressure is below the saturation pressure of the used liquid, an intensive evaporation of fluid occurs, along with the formation of cavitation bubbles. For different cases can be the formation and intensity of the cavitation described, just by the criterion of similarity, called cavitation number. The equation for our case is (4). $[3,17]$

$$
\sigma=\frac{p_{0}-p_{v}}{\rho \frac{v^{2}}{2}}
$$

\section{$3 \quad$ Numerical model}

The three-dimensional geometry of the numerical model consists of two cylindrical walls placed concentrically (Fig.1). The inner wall of known geometry rotates with specific angular velocity. The outer cylindrical wall, also of known geometry, is stationary. The volume between the two cylindrical walls is filled with water of constant temperature, density and viscosity.

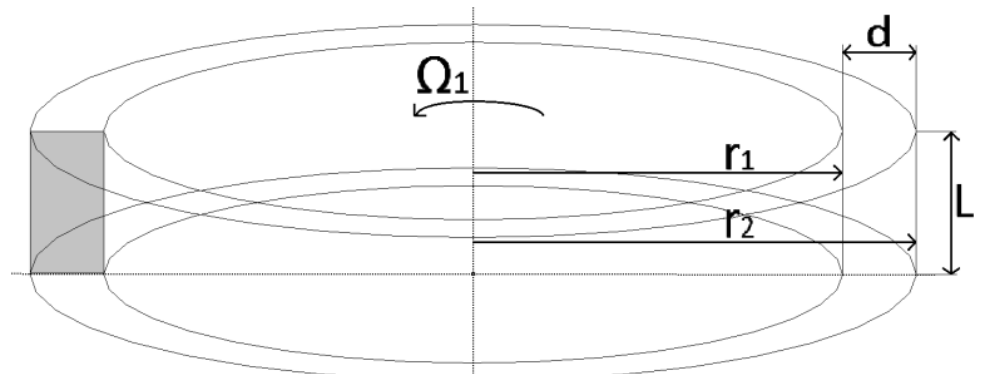

Fig. 1. The geometry of the numerical model (radius of inner cylinder $r_{1}$, radius of outer cylinder $r_{2}$, cylinder height $L$, gap between the two cylinders d, angular velocity of inner cylinder $\Omega_{1}$ ) 
The computational mesh for the given geometry was generated from hexahedral elements with total number of 501220 (Fig.2). Maximum size of elements was set to $0.1 \mathrm{~mm}$. The thickness of the first element in the boundary layer at all solid walls was set to $0.005 \mathrm{~mm}$. This size was determined by calculation of the criterion $Y^{+}<40$. The growth of elements was constant throughout the volume $(1.2)$. $[4,5]$
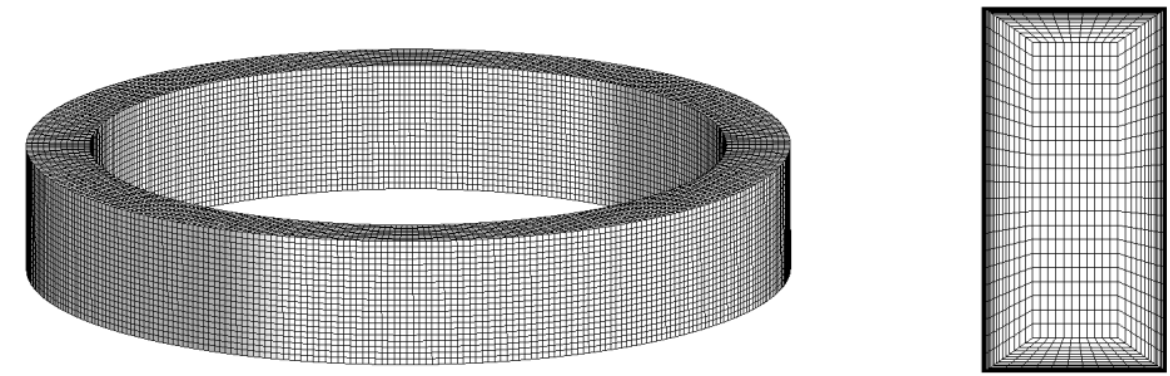

Fig. 2. Computational mesh of the numerical model in isometric and sectional view

For this task we had to choose from several models of turbulence. The most accurate results comparable with laboratory experiments can be achieved by DNS (Direct Numerical Simulation) direct model, however this needs huge computational power. Very accurate results are obtained from the LES (Large Eddy Simulation) turbulence model, which separates the large vortices from the small ones. Then the small vortices are solved similar as with the RANS (Reynolds Averaged Navier-Stokes) type method. Model LES is also very dependent on computational power. From RANS type models, which are solving time averaged NavierStokes equations, for this numerical problem, models RSM (Reynolds Stress Model) and k- $\omega$ SST (Shear Stress Transport) are usable. RSM model has twelve equations, that works on the basis of Reynolds stresses. It works with high precision only for simple geometric tasks. The last of the mentioned models, $\mathrm{k}-\omega \mathrm{SST}$ is the most preferred one in terms of computational time, because it is a two-equation model. This model has been designed to effectively connect the robustness and accuracy of the model k- $\omega$ in areas close to the wall with model k- $\varepsilon$, which works better in a free flow away from the walls. For this numerical task k- $\omega$ SST model turbulence was used, because the almost identical results compared with the more complex RMS model, and its low demands on computational power. [6, 7, 8]

For simulation of formation and progress of the cavitation the Rayleigh-Plessey equation was used, which simplifies the physical conditions such as temperature, density, dynamic viscosity and makes them independent from the time change. This equation also assumes the uniform distribution of pressure and temperature on the surface of the cavitation bubble. [9, 10]

Among individual calculations the velocity of the inner cylindrical wall was altered in the range from $10000 \mathrm{RPM}$ up to $500000 \mathrm{RPM}$. The value of the reference static pressure was set to the value of atmospheric pressure. As the working fluid was water $\left(t=25^{\circ} \mathrm{C}\right)$ was selected, which has a critical vapor pressure of $p_{v}=3169 \mathrm{~Pa}$.

\section{Results}

From numerical calculations the results of the static pressure on a rotating wall (Fig.3), on stationary wall (Fig.3) and in the volume filled with water (Fig.4) were processed. With gradually increasing rotational velocity, the static pressure on a rotating wall decreases until it reaches the critical level for water at a given temperature. After exceeding this value, the progress of static pressure on inner wall, can be described by a straight line in the form: $\mathrm{y}=$ const. The static pressure on the stationary wall after exceeding the critical pressure 
changes its character, which is reflected in a slower growth of static pressure to rotational velocity.

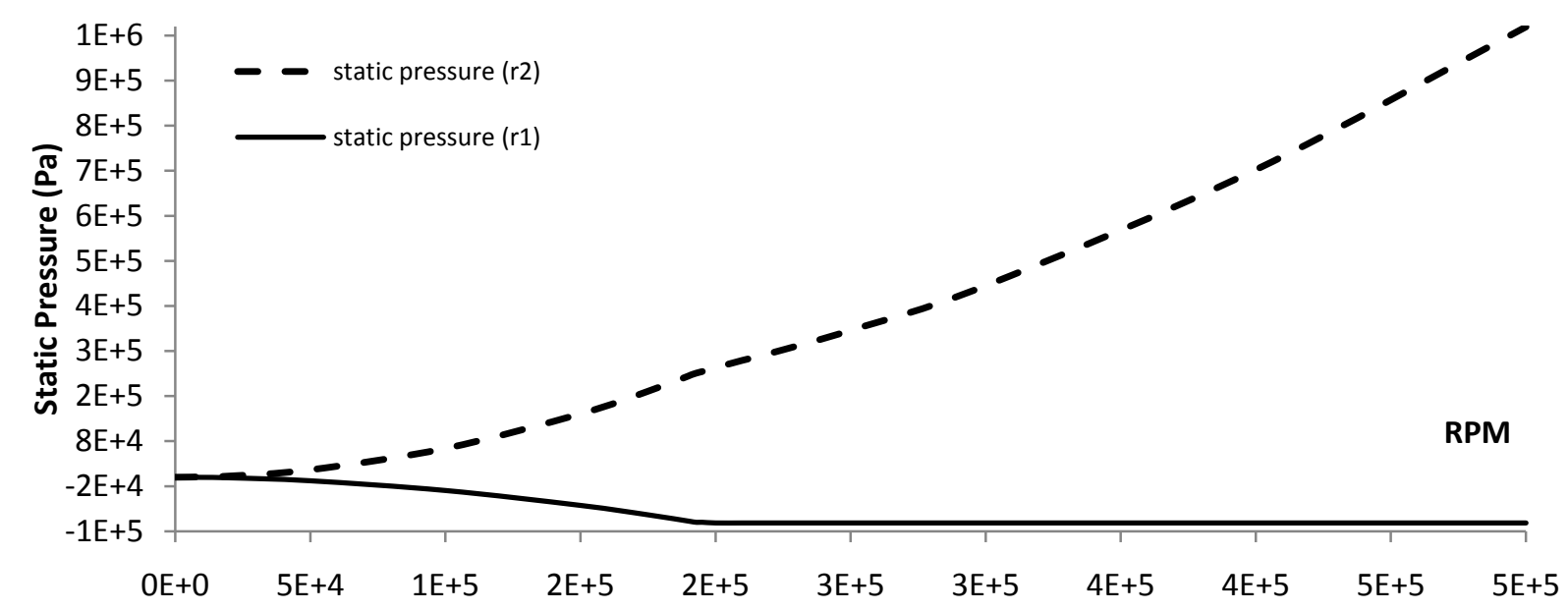

Fig. 3. Curve of minimum static pressure on the rotating inner cylinder (solid), Curve of maximum static pressure on the stationary outer cylinder (dashed)

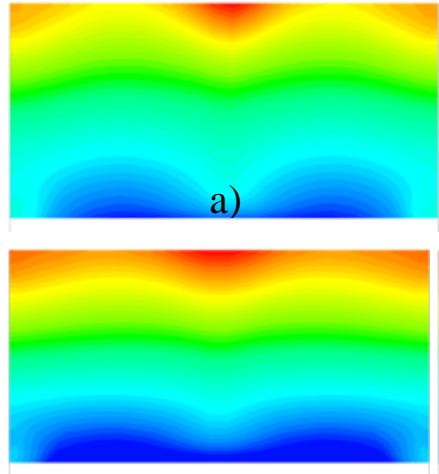

d)

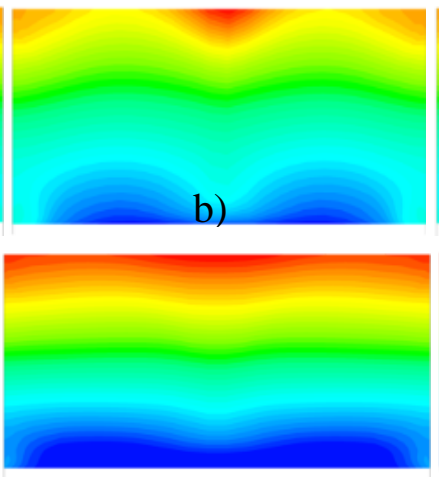

e)
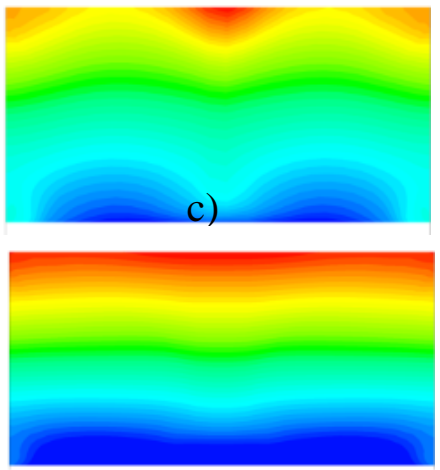

f)

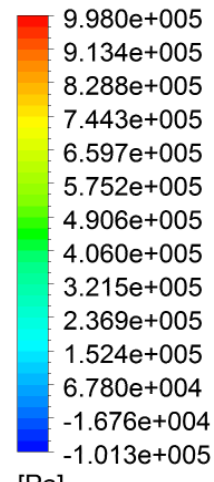

$[\mathrm{Pa}]$

Fig. 4. Pressure fields in the narrow gap in section view, a) 190000 RPM, b)

$195000 \mathrm{RPM}$

c) $200000 \mathrm{RPM}$, d) $300000 \mathrm{RPM}$, e) $400000 \mathrm{RPM}$, f) $500000 \mathrm{RPM}$

Visualizations of the velocity fields and vectors shown in section view of narrow gap between cylindrical walls (Fig.5 and Fig.6) indicates the formation of the Taylor vortices, which can be described as the interaction of centrifugal and viscous forces. The intensity of these vortices can be characterized by a so-called Taylor number (equation 5), where $\eta$ is the radius ratio of the inner and outer cylinder $r_{1} / r_{2}$. The given equation for Taylor number is specific for the actual type of task, where the inner cylindrical wall rotates at constant velocity and the outer cylindrical wall remains stationary. [11]

$$
T a=4 R e^{2}\left(\frac{1-\eta}{1+\eta}\right)
$$

After determining the absolute pressure from numerical simulations, it was possible to plot the curve for dependence of rotational velocity of inner cylindrical surface and cavitation number (Fig.6). The curve has a hyperbolic shape at the beginning, until the value of cavitation number falls below 1, which indicates the start of cavitation process. With further increase of the rotational velocity, and lowering the static pressure, the cavitation number exponentially approaches value 0 . Cavitation inception is accompanied by nucleation of steam bubbles. The amount of water vapor in unit volume of the fluid can be expressed by volume 


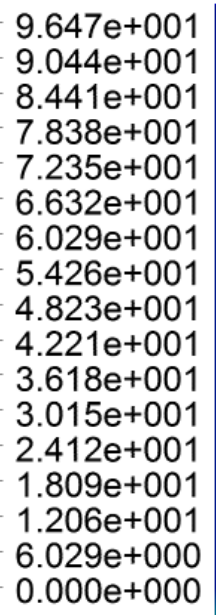

Fig.5. Velocity fields and vectors of a tangential components of velocity 190000 RPM, in regime without cavitation

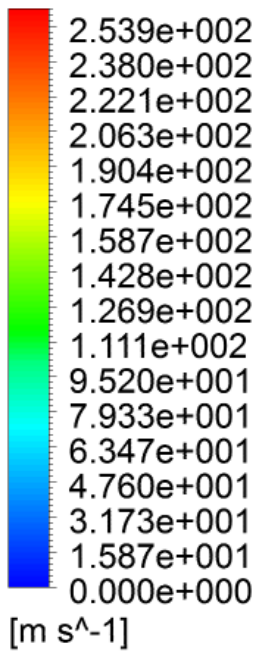

Fig.6. Velocity fields and vectors of a tangential components of velocity 500000 RPM, in a cavitation regime

fraction depending on the rotational velocity of the inner wall (Fig.7). In case of static pressure drop below the critical value, the volume fraction of the water vapor significantly increases together with the increasing rotational velocity. The progress is linear at the beginning, up to the value 0.4. Beyond this value, the increasing of the volume fraction is slowing down.

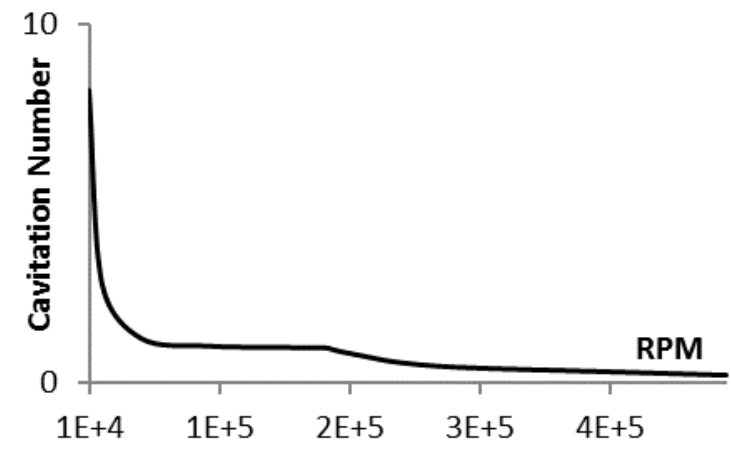

Fig. 7. Dependence of cavitation number and rotational velocity of the inner cylinder

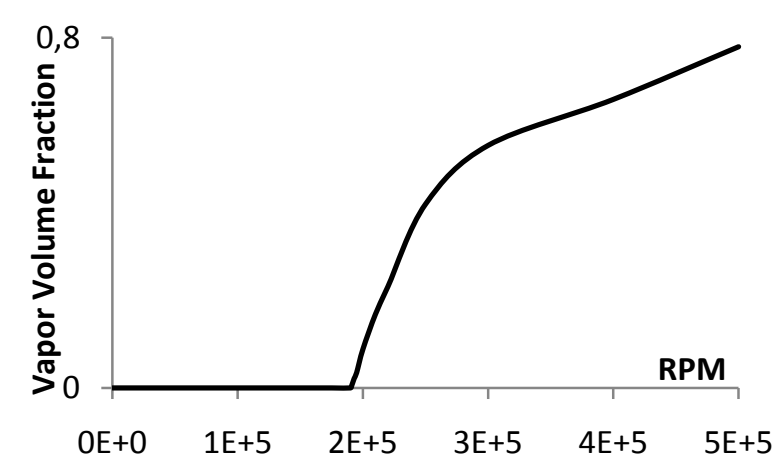

Fig. 8. Dependence of water vapor volume fraction and rotational velocity of the inner cylinder 
The following visualizations display the section views of narrow gap between cylindrical surfaces and the volume fraction of water vapor evolving in dependence on rotational velocity of the inner wall. In (Fig.8.b) an early stage of cavitation, at the velocity of 195000 RPM is shown. With increasing rotational velocity, the volume fraction of water vapor significantly increases (Fig.8.c-f), as was previously described.

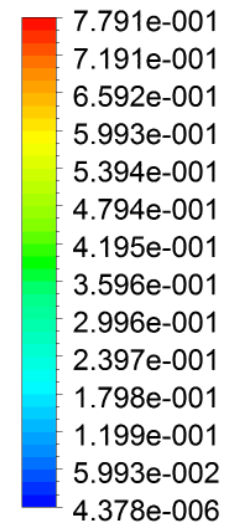

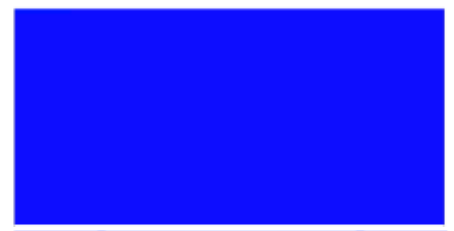

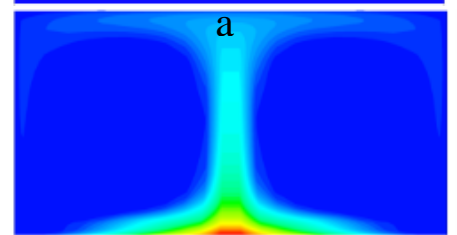

d)

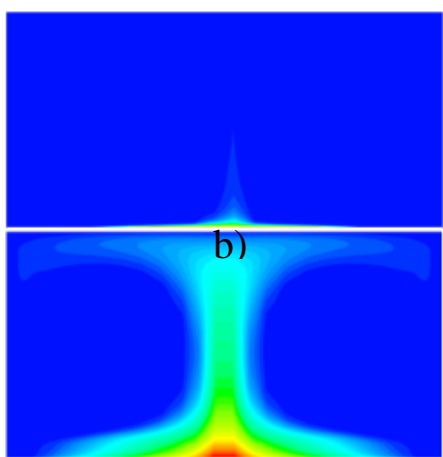

e)

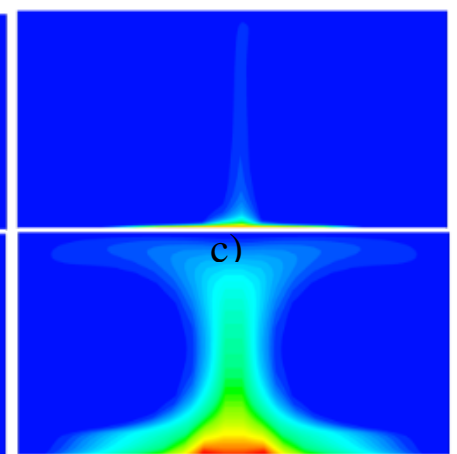

f)

Fig. 9. The volume fraction of water vapor at different rotational velocity of the inner cylinder, viewed at narrow gap in a section view, a) 190000 RPM, b) 195000 RPM d) 200000 RPM, e) 300000 RPM, g) 400000 RPM, h) 500000 RPM

On visualizations (Fig.9) we can see the inner rotating cylinder and the volume of liquid, which contains water vapor with a minimum volume fraction of 0.1 , at different rotational velocity of the inner cylinder. From the visualizations can be observed, that the place of formation of the cavitation for this test case, is the surface of the inner cylinder, specifically the center of the cylinder in the direction of axis $\mathrm{z}$. Location is conditioned by the tangential component of the velocity vector of the fluid stream, which causes, that the static pressure is the lowest in this place.

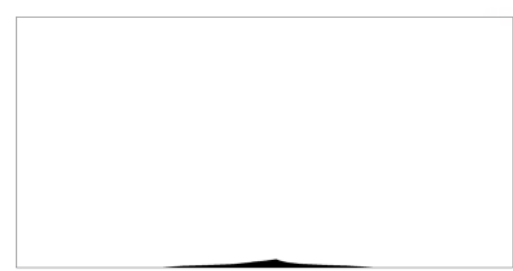

a)

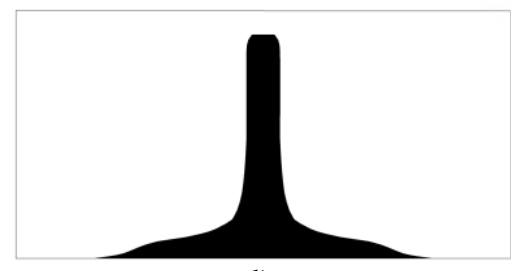

d)

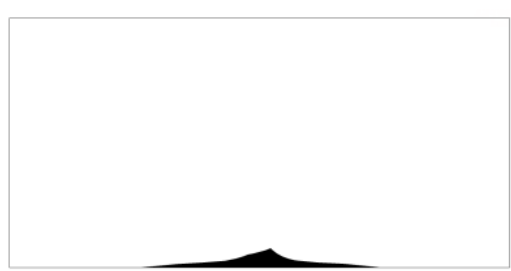

b)

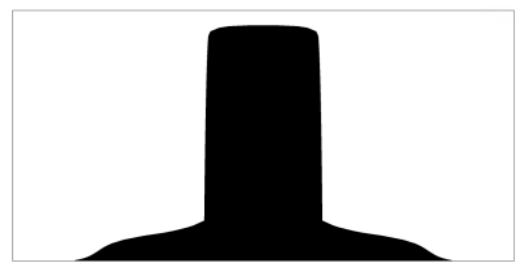

e)

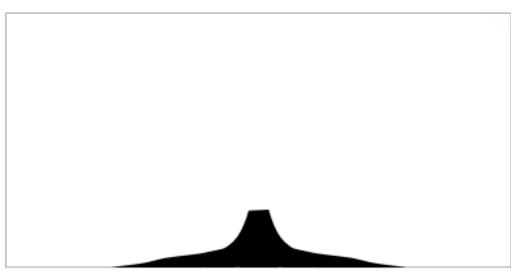

c)

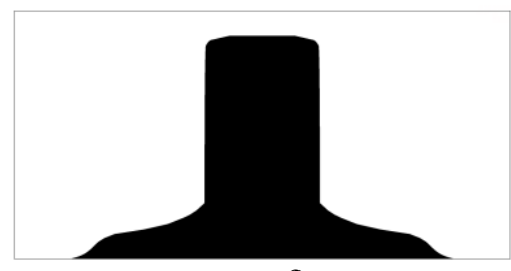

f)

Fig. 10. The distribution of liquid volume with a minimum volume fraction of water vapor 0.1, viewed at narrow gap in a section view, a) 195000 RPM, b) 200000 RPM, c) $250000 \mathrm{RPM}$, d) $300000 \mathrm{RPM}$, e) $400000 \mathrm{RPM}, \mathrm{f}) 500000 \mathrm{RPM}$

\section{Proposal of experimental circuit}

Proposal of the experimental circuit mainly includes a proposal of hydraulic part, which is a test cell made of a transparent material (space between the two concentric cylinders with the stationary outer surface and the rotating inner surface rotates. The rotating cylinder is driven 
by PMSM (synchronous motor with permanent magnets), which is controlled by three-phase sinusoidal signals. The motor needs a special controller (vector control system) and precisely adjustable DC voltage source. PMSM motor has a feedback for accurate detection of rotational speed. [12]

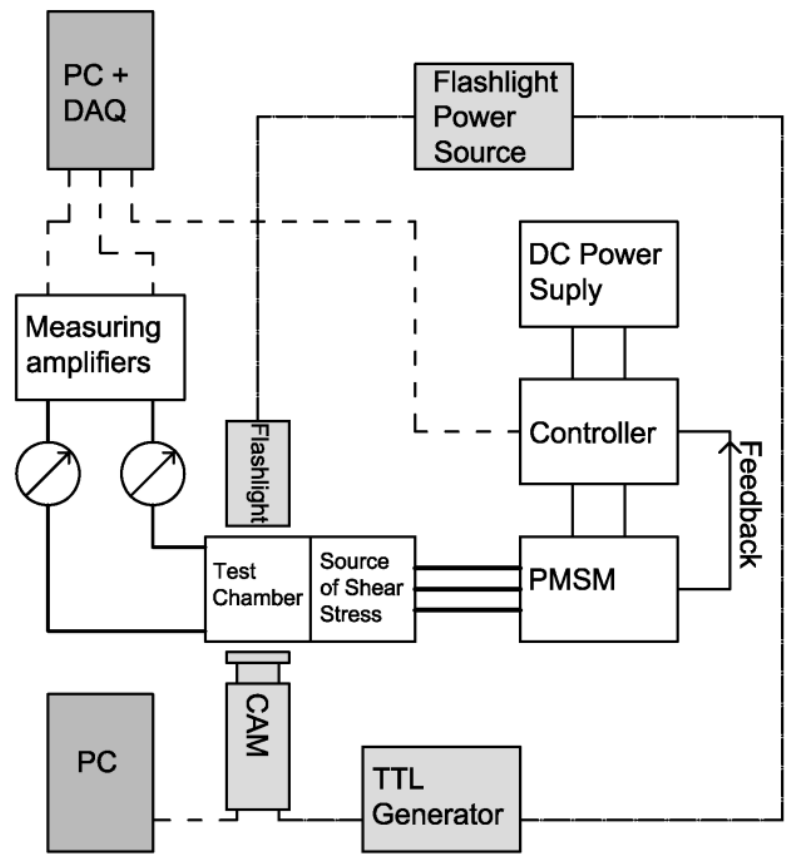

Fig. 11. Experimental circuit schematic (hydraulic part, measuring and control part, recording part)

The measuring and the control part of the experimental circuit has two pressure sensors in the test cell, which are connected to the measuring amplifier. The measuring DAQ system is connected to the PC. The controller part is necessary to control the rotation speed and torque of the electric motor PMSM. This is allowed by interface controller - PC equipped with the necessary software. The measured values of static pressure allow us to verify the characteristics of pressure to the circumferential speed of CFD numerical calculations. [13]

The recording part consist of the high-speed digital camera which is able to take pictures in a very short period of time. This needs a powerful external light source. Which will emit flashes of light synchronously with the exposure time of the camera. The time step of the camera is transmitted to the TTL pulse generator serving as input signal for the power supply of stroboscopic lighting of the test chamber. [14]

On the fig. 11. and 12. is a proposal of experimental device displayed. In the proposal are included all the elementary parts of the device required for the cavitation generation at high shear stress. The main moving parts are the rotor of the motor and the shaft of the experimental device, which transfers the needed amount of kinetic energy to the fluid. The kinetic energy conserved in the fluid is then due to the friction between the molecules transformed to heat. The transparent testing chamber enables to monitor the cavitation occurred in the narrow gap between the two cylinders. The ceramic ball bearing prevents the radial movement of the rotating cylinder. The rotating cylinder will be driven by a high-speed electric motor PMSM. The rest of the parts have support function $[15,16]$. 


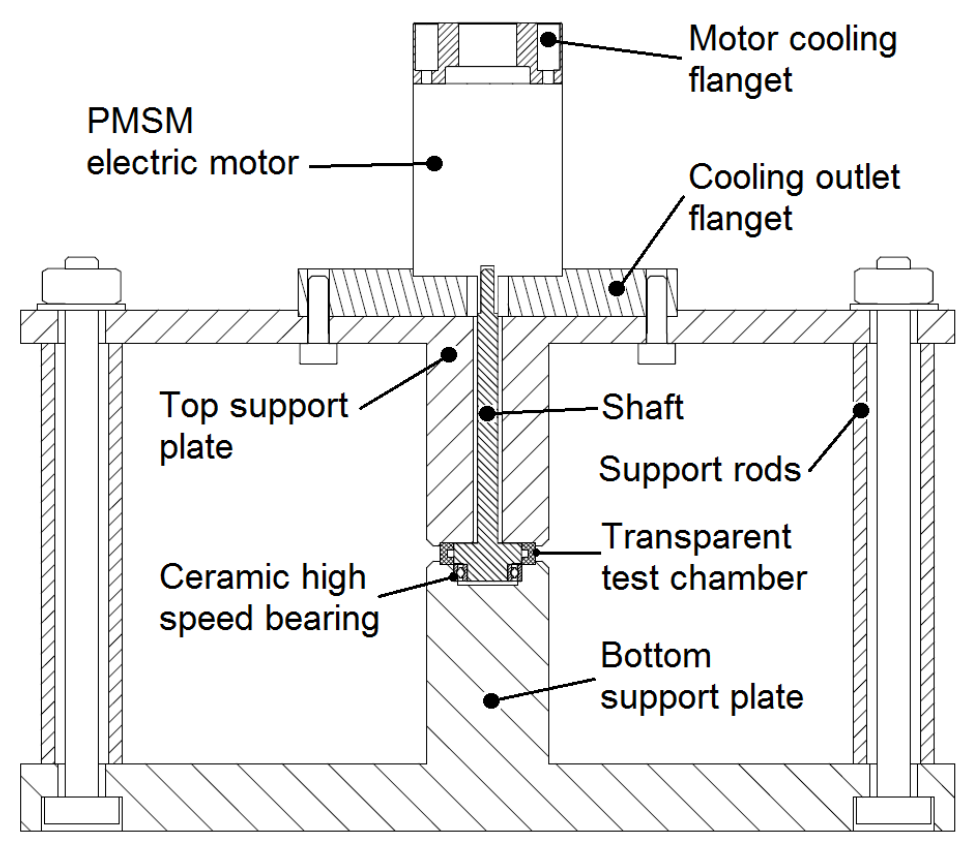

Fig. 12. Section view of experimental device for physical visualization of the cavitation induced at high values of shear stress

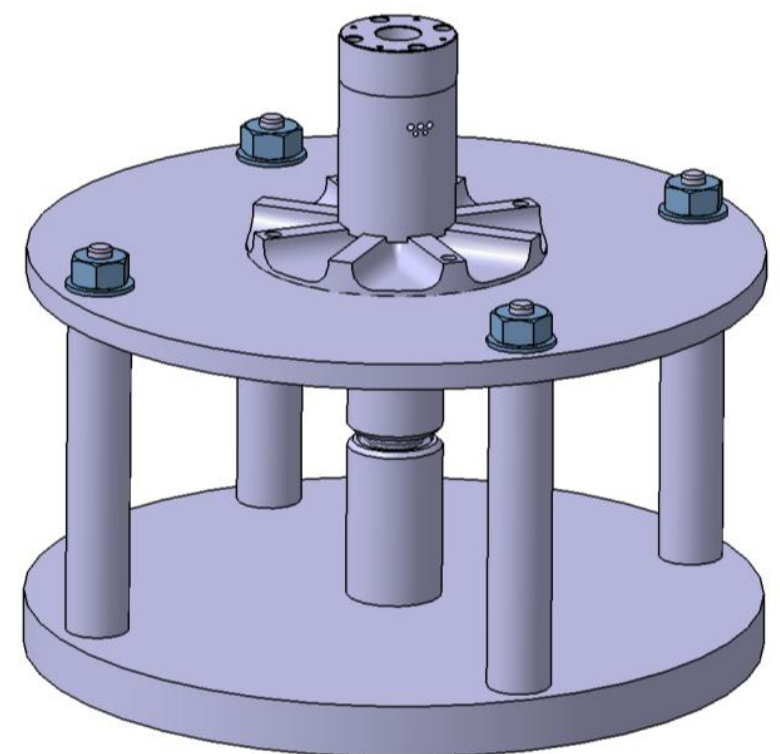

Fig. 13. 3D model of experimental device for physical visualization of cavitation induced at high values of shear stress

\section{Conclusion}

The case of inception of cavitation due to shear stress was solved by the method CFD. From the results of numerical simulations is evident, that the influence of this effect can be developed at a physical achievable circumferential velocity to, due to the low static pressure, in water with constant temperature $25^{\circ} \mathrm{C}$, create cavitational bubbles. Change in the static pressure depends on the velocity difference between the two solid cylindrical walls, which are in interaction with a viscous fluid filling the volume of the narrow gap between them. In addition to the phenomenon of cavitation during the numerical calculations, it was possible to detect the presence of Taylor vortices, which arise depending on the current action of inertial 
and viscous forces in the fluid. In the cavitation regime these vortices were suppressed as a result of formation of the cavitation bubbles, which have different physical properties compared to water in liquid state. According to the results from CFD calculations was an experimental device for cavitation research at high stress shear was designed. The resources necessary to the visualization of the cavitation phenomenon were chosen. The cavitation generator is due to the transparent testing chamber constructionally adjusted for monitoring the cavitation with the help of a high-speed digital camera. The results from the experiments will be presented after the assembly of the cavitation generator and the completion of the required experiments.

\section{References}

[1] URUBA, V.: Turbulence, ČVUT in Praha, Faculty of Mechanical Engineering, 2009, No. 1., 130 pp., ISBN 978-80-01-04330-1, Czech republic

[2] OLŠIAK, R.: Experimentálne zariadenie na výskum prúdenia v kanáloch vel'mi malých rozmerov, The application of experimental and numerical methods in fluid mechanics and energetics, Proceedings XVII. International scientific conference, Žilina 2010, pp. 238, ISBN 978-80-554-0189-8

[3] BRENNEN, E.B.: Cavitation and Buble Dynamics, ISBN 978-01-95-09409-1, s.282, Oxford University Press, Oxford 1995, United Kingdom

[4] Fluent Inc. Fluent 15 -Theory guide. [Online]. c2015, Acess from URL: http://148.204.81.206/Ansys/150/ANSYS\%20Fluent\%20Users\%20Guide.pdf

[5] KOZUBKOVÁ, M.; RAUTOVÁ, J.; BOJKO, M.: Mathematical Model of Cavitation and Modelling of Fluid Flow in Cone, Conference "HERVICON-2011", Ostrava Poruba 708 33, Czech republic 2011

[6] DJERIDI, H., GABILlET, C., BILlARD, J. Y.: Two-Phase Couette Taylor Flow: Arrangement of the Dispersed Phase and Effects on the Flow Structures, Research Institute of French Naval Academy, France 2004

[7] BRUJAN, E. A.: Cavitation in Non-Newtonian Fluids - With Biomedical and Bioengineering Applications, Springer Science 2011, ISBN 978-3-642-15342-6

[8] VLČEK, P.: Modelování turbulentního proudění, ČVUT in Praha, Faculty of Mechanical Engineering, 2013, Czech Republic, Access from URL: http://chps.fsid.cvut.cz/pt/2013/pdf/3509.pdf

[9] SHAH Y. T., PANDIT A. B., MOHOLKAR V. S.: Cavitation Reaction Engineering, Springer US 1999, Vyd.1., 352pp., New York USA, ISBN 978-1-4615-4787-7

[10] FRANC J.P., MICHEL J.M.: Fundamentals of Cavitation, Springer Science \& Business Media, 2006, Vyd.1., 306 pp., Netherland, ISBN 978-1-4020-2233-3

[11] ATTIA, H. A., ABDEEN, M. A. M.: Unsteady generalized Couette flow with heat transfer considering the Hall effect, Journal of Mechanical Engineering, 62, 2011, pp. 5-6, ISSN: 0039-2472, Slovak republic

[12] GUILLERM R., DA SOGHE R., BIANCHINI C., PONCET S., VIAZZO S.: Numerical predictions of flow field in closed and opened Taylor-Couette cavities, 4th european conference for aerospace sciences (EUCASS 2011), Saint Petersburg 196084, Russia 2011, Acess from URL: https://www.academia.edu/1416115//Numerical_ predictions_of_flow_field_in_closed_and_opened_Taylor-Couette_cavities 
[13] DJERIDI H., GABILlET C., BILlARD J. Y.: Two-Phase Couette Taylor Flow: Arrangement of the Dispersed Phase and Effects on the Flow Structures, Research Institute of French Naval Academy, France 2004, Access from URL: https://hal.archives-ouvertes.fr/hal-01208349/document

[14] DIJKINK R. J.: Confined cavitation an experimental study, University of Twente, Netherland 2009, ISBN 978-90-365-2822-1

[15] DAVID ANDERECK C., HAYOT F.: Ordered and Turbulent Patterns in TaylorCouette Flow, Nato Science Series B, Springer US, Vyd.1., 357pp., USA 1992, ISBN 978-1-4615-3438-9

[16] MĹKVIK M., OLŠIAK R., KNÍŽAT B.: Rozrušovanie pevných materiálov pomocou kavitácie, Slovak Technical University in Bratislava, Faculty of Mechanical Engineering, No.1., 99.pp., Slovak republic 2015, ISBN 978-80-227-4323-5

[17] GOGA V., HUČKO B.: Phenomenological Material Model of Foam Solids. In Journal of Mechanical Engineering - Strojnícky časopis, Vol. 65, No. 1, 2015, pp.5-20, ISSN 0039-2472 